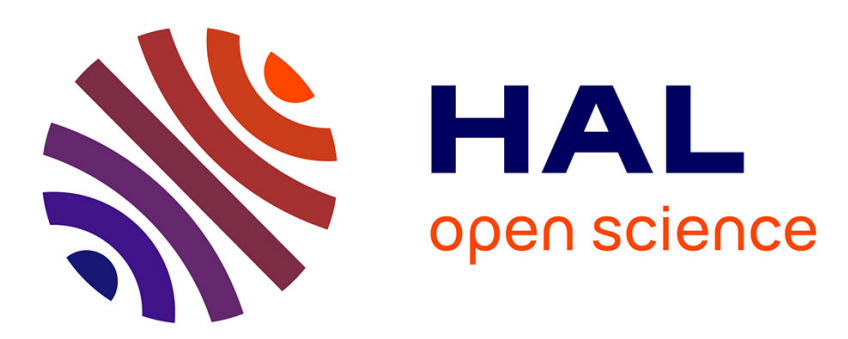

\title{
Simulation of the deflected cutting tool trajectory in complex surface milling
}

Moez Smaoui, Zoubeir Bouaziz, Ali Zghal, Gilles Dessein, Maher Baili

\section{To cite this version:}

Moez Smaoui, Zoubeir Bouaziz, Ali Zghal, Gilles Dessein, Maher Baili. Simulation of the deflected cutting tool trajectory in complex surface milling. International Journal of Advanced Manufacturing Technology, 2011, vol. 56, pp. 463-474. 10.1007/s00170-011-3213-x . hal-00793552

\section{HAL Id: hal-00793552 https://hal.science/hal-00793552}

Submitted on 22 Feb 2013

HAL is a multi-disciplinary open access archive for the deposit and dissemination of scientific research documents, whether they are published or not. The documents may come from teaching and research institutions in France or abroad, or from public or private research centers.
L'archive ouverte pluridisciplinaire HAL, est destinée au dépôt et à la diffusion de documents scientifiques de niveau recherche, publiés ou non, émanant des établissements d'enseignement et de recherche français ou étrangers, des laboratoires publics ou privés. 


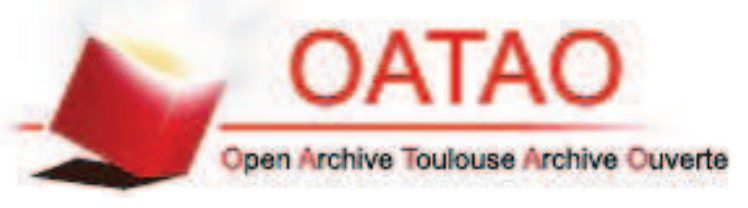

\section{Open Archive TOULOUSE Archive Ouverte (OATAO)}

OATAO is an open access repository that collects the work of Toulouse researchers and makes it freely available over the web where possible.

This is an author-deposited version published in : http://oatao.univ-toulouse.fr/ Eprints ID : 8438

To link to this article : DOI: $10.1007 / \mathrm{s} 00170-011-3213-\mathrm{x}$

URL : http://dx.doi.org/10.1007/s00170-011-3213-x

To cite this version : Smaoui, Moez and Bouaziz, Zoubeir and Zghal, Ali and Dessein, Gilles and Baili, Maher Simulation of the deflected cutting tool trajectory in complex surface milling. (2011) The International Journal of Advanced Manufacturing Technology, vol. $56\left(\mathrm{n}^{\circ} 5-8\right)$. pp. 463-474. ISSN 0268-3768

Any correspondence concerning this service should be sent to the repository administrator: staff-oatao@,listes.diff.inp-toulouse.fr 


\title{
Simulation of the deflected cutting tool trajectory in complex surface milling
}

\author{
Moez Smaoui • Zoubeir Bouaziz • Ali Zghal • \\ Gilles Dessein • Maher Baili
}

\begin{abstract}
Since industry is rapidly developing, either locally or globally, manufacturers witness harder challenges due to the growing competitivity. This urges them to better consider the four factors linked to production and output: quality, quantity, cost and price, quality being of course the most important factor which constitutes their main concern. Efforts will be concentrated - in this research — on improving the quality and securing more accuracy for a machined surface in ball-end milling. Quality and precision are two essential criteria in industrial milling. However, milling errors and imperfections, due mainly to the cutting tool deflection, hinder the full achieving of these targets. Our task, all along this paper, consists in studying and realizing the simulation of the deflected cutting tool trajectory, by using the methods which are available. In a future stage, and in the frame of a deeper research, the simulation process will help to carry out the correction and the compensation of the errors resulting from
\end{abstract}

M. Smaoui $\cdot$ Z. Bouaziz $(\bowtie) \cdot$ A. Zghal

Unité de Recherche de Mécanique des Solides,

des Structures et de Développement Technologiques, ESSTT,

Tunis, Tunisia

e-mail: zoubeir.bouaziz@enis.rnu.tn

M. Smaoui

e-mail: Smaouimoez@voila.fr

A. Zghal

e-mail: ali.zghal@esstt.rnu.tn

G. Dessein · M. Baili

Laboratoire Génie de Production,

Ecole Nationale d'Ingénieurs de Tarbes,

47 Avenue Azereix, BP 1629,

65016 Tarbes Cedex, France

G. Dessein

e-mail: gilles.dessein@enit.fr

M. Baili

e-mail: Maher.Baili@enit.fr the tool deflection. The corrected trajectory which is obtained by the method mirror will be sent to the machine. To achieve this goal, the next process consists - as a first step-in selecting a model of cutting forces for a ball-end mill. This allows to define - later on - the behavior of this tool, and the emergence of three methods namely the analytical model, the finite elements method, and the experimental method. It is possible to tackle the cutting forces simulation, all along the tool trajectory, while this latter is carrying out the sweeping of the part to be machined in milling and taking into consideration the cutting conditions, as well as the geography of the workpiece. A simulation of the deflected cutting tool trajectory dependent on the cutting forces has been realized.

Keywords Milling · Cutting forces · Tool deflection · CAM

\section{Introduction}

Improving the machined surface quality and seeking a greater precision constitute the major aim of the industrial researchers [1]. However, the latter often find themselves confronted with several obstacles, such as milling errors and adjacent imperfections [2]. Hence, these undesirable factors are not integrated in the software CAD/CAM. This leads researchers to think and propose new methods tending to provide more precision by correcting and compensating these errors [3].

Kang [4] has provided useful information for the database related to accuracy, roughness, and wear in the case of inclined surface milling.

In the case of ball-end milling and particularly the use of slender tools and the manufacture of complex molds, the tool deflection remains the main cause of these errors. It has a direct effect on the machined surface. For this reason, an off-line compensation has been proposed $[5,6]$. 
The methodology of the trajectory compensation, simulated by CAM is carried out in three steps: the modeling of cutting forces [7], the calculation of the tool deflection [8,9], and the error compensation [3].

In this context, it is necessary to establish a program for the simulation of the cutting tool deflected trajectory. It is concerned with the relation between the cutting forces and the tool deflection which is object to modify the machining trajectory.

According to Seo $[10,11]$, the tool deflection can be determined by three factors: the tool geometry modeling, the cutting forces modeling, and finally the methodology of the tool deflection calculation. He has carried out four rectilinear machinings in order to establish the nearest possible estimation of the tool deflection. He has started with changing the axial depth of cut, and this is done by adding - each time - an increment of $1 \mathrm{~mm}$. His work does not take into consideration the spindle deflection.

Kim [12] has presented a method to analyze the form of a tridimensional error of a surface machined with a ball-end mill. This error is due to the elastic compliance of the tool. To estimate this error, Kim has established the cutting forces and the tool deflection model. He has taken into account the inclination angle of the surface machining.

He has stated that the deflection of both tool and tool holder is mainly due to the cutting force horizontal component. He has presumed that the axial deflection of the tool system is generally negligible, taking into consideration the importance of the stiffness in this direction. The tool total deflection is the sum total of the tool deflection and that of the clamping zone. Salgado [13] has developed this idea to prove that the deflection error comes not only from the couple tool holder/ tool but also from the couple spindle/tool holder. He has achieved a series of tests for tools of different diameters, based on the principle of applying a force measured by a Kistler dynamometric plate. The displacement is evaluated by a sensor applied onto the tool.

The experimental tests, compared to the two methods: analytical model (AM) and finite elements method (FEM), have engendered an error of $40 \%$ according to the AM and an error of $25 \%$ according to the FEM. As a result, he has proposed a model of the set stiffness calculation: tool/tool holder. This model has been inspired from a series of tests applied into two different tool holders, so as to measure the displacement in four different zones of the set.

In this context, we propose a simulation of the deflected cutting tool trajectory which is depending on the cutting forces. The latter are calculated at all points of the trajectory at the time of machining. This simulation will be of a great contribution, especially when envisaging, in a future step of this research, to correct and compensate the cutting tool trajectory. A compensation algorithm, inspired from the mirror method, is going to be adopted. It will allow correcting the tool-deflected trajectory all along the part.

The new coordinates of the compensated trajectory are to be exported towards the CAM software (MasterCam $\subset$ ), then towards the machine.

For this, a calculation model of the deflection $\mathrm{dx}$, dy, and $\mathrm{dz}$ is going to be defined, respectively, in the three directions $X, Y$, and $Z$ depending on the cutting forces $F_{\mathrm{x}}$, $F_{\mathrm{y}}$, et $F_{\mathrm{z}}$. This model will take into account the application point of these forces which varies according to the trajectory inclination angle.

Two calculation methods of the tool deformation are presented namely the AM calculation method and the FEM.

Following an experimental test, the obtained results are rigorously evaluated and compared.

\section{Cutting forces model}

In order to achieve the modeling of the cutting forces, it is essential to know very well the geometry of the tool spherical part [14]. The cutting edges engaged in the material at an axial depth of cut $A_{d}$, are decomposed into $N_{z}$ elementary cutting edges (which are supposed to be linear according to an axial discretization increment $d z$ ) where each of which bears the index $i\left(i=1,2, \ldots, N_{z}\right)$ (see Fig. 1).

$d z=\frac{A_{d}}{N_{z}}$

For an elementary cutting edge, we introduce a spherical coordinate system $\Re_{\mathrm{S}}$, having as origin the spherical part center "C" and the unitary local vectors $(\vec{R}, \vec{T}, \vec{A})$ which follow respectively the radial direction, the decreasing $\beta$ direction, and the increasing $\eta$ direction.

The angle $\phi_{p}$ is defined as being the angle between two consecutive teeth. And if we decompose $\phi_{p}$ in $N_{\theta}$ increments, each of these increments will be represented by the index $j\left(j=1,2, \ldots, N_{\theta}\right)$.

Three components with an infinitesimal force are locally defined at a point $\mathrm{P}$ (middle of the disk) of the cutting edge $K\left(K=1 \ldots N_{f}\right)$, with $N_{f}$ is the number of teeth. These three components $F_{\mathrm{R}}, F_{\mathrm{T}}$, and $F_{\mathrm{A}}$ are defined in the local coordinate system $\Re_{\mathrm{S}}$, according to Fig. 2 .

The equations of the elementary radial, tangential, and axial cutting forces [7], represented in Fig. 2 are:

$\left\{\begin{array}{l}d F_{R}=K_{R} f_{z_{b}} \sin \beta d z \\ d F_{T}=K_{T} f_{z_{b}} \sin \beta d z \\ d F_{A}=K_{A} f_{z_{b}} \sin \beta d z\end{array}\right.$

Where $K_{R}$ is the specific radial coefficient, $K_{T}$ is the specific tangential coefficient and $K_{A}$ the specific axial coefficient; $f_{z_{b}}$ is the advance by tooth. 
Fig. 1 The cutting edge discretization

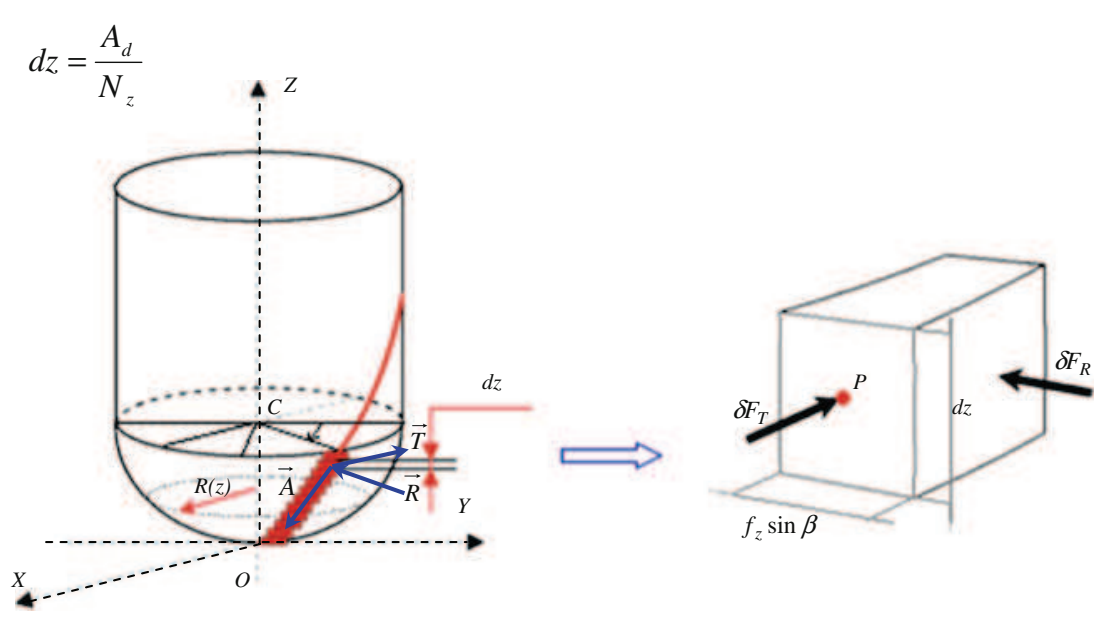

The equation generalized for the elementary radial, tangential, and axial cutting forces is given by:

$$
\left\{\begin{array}{l}
d F_{R}(i, j, k)=K_{R} f_{z_{b}} \sin [\beta(i, j, k)] d z \\
d F_{T}(i, j, k)=K_{T} f_{z_{b}} \sin [\beta(i, j, k)] d z \\
d F_{A}(i, j, k)=K_{A} f_{z_{b}} \sin [\beta(i, j, k)] d z
\end{array}\right.
$$

The total cutting force for the angular position $(j)$ is:

$$
\left[\begin{array}{l}
d F_{x}(j) \\
d F_{y}(j) \\
d F_{z}(j)
\end{array}\right]=\sum_{i=l}^{N_{z}} \sum_{k-l}^{N_{f}}[T]_{\Re_{C}}^{\Re_{S}}(i, j, k)\left[\begin{array}{c}
K_{R} \\
K_{T} \\
K_{A}
\end{array}\right] f_{z_{b}} \sin [\beta(i, j, k)] d z
$$

With $[T]_{\Re_{C}}^{\Re_{S}}$ the matrix of the transformation from $\Re_{\mathrm{S}}$ $(\mathrm{C}, \vec{R}, \vec{T}, \vec{A})$ to $\Re_{\mathrm{C}}(\mathrm{O}, \mathrm{X}, \mathrm{Y}, \mathrm{Z})$ such as:

$$
[T]_{\Re_{C}}^{\Re_{S}}=\left[\begin{array}{ccc}
-\sin \eta \sin \beta & -\cos \beta & -\cos \eta \sin \beta \\
-\sin \eta \cos \beta & \sin \beta & -\cos \eta \cos \beta \\
\cos \eta & 0 & -\sin \eta
\end{array}\right]
$$

To carry out the simulation of the cutting forces, it is necessary, first of all, to determine specific coefficients resulted from the experimental tests and depended on the couple tool/material. Any change affecting one of these elements will inevitably affect these coefficients. In the experiment, a ball-end mill with a diameter of $16 \mathrm{~mm}$ and an apparent length equal to $80 \mathrm{~mm}$, is used to realize the milling of a workpiece, made of steel of the type XC38 (C35: new designation), as shown in Fig. 3.

The cutting conditions are defined by an axial path depth $A_{d}=1 \mathrm{~mm}$, a total radial engagement of the tool $A_{r}=2 . R_{0}$, a feed per tooth $f_{\mathrm{zb}}=0.1 \mathrm{~mm} /$ tooth and a spindle speed equal to $4,000 \mathrm{rpm}$ on a numerical control machine tool of the type HURON KX 10 .

Figure 4 presents the result of the cutting forces which is given by the test we have realized. These cutting forces are applied onto the dynamometric plate and not on the tool. It is to note that the landmark conceived by the manufacturer of the dynamometric plate, is directed towards the bottom. This explains the reason why the forces $F_{\mathrm{x}}$ and $F_{\mathrm{y}}$, represented in the figure, are of opposite signs in comparison to the simulated forces exerted on the tool.

The experimental oscillation of the cutting forces show the dynamic or vibratory phenomenon caused by the whole machine-tool structure.
Fig. 2 Cutting forces applied onto the tool at a point $\mathrm{P}$
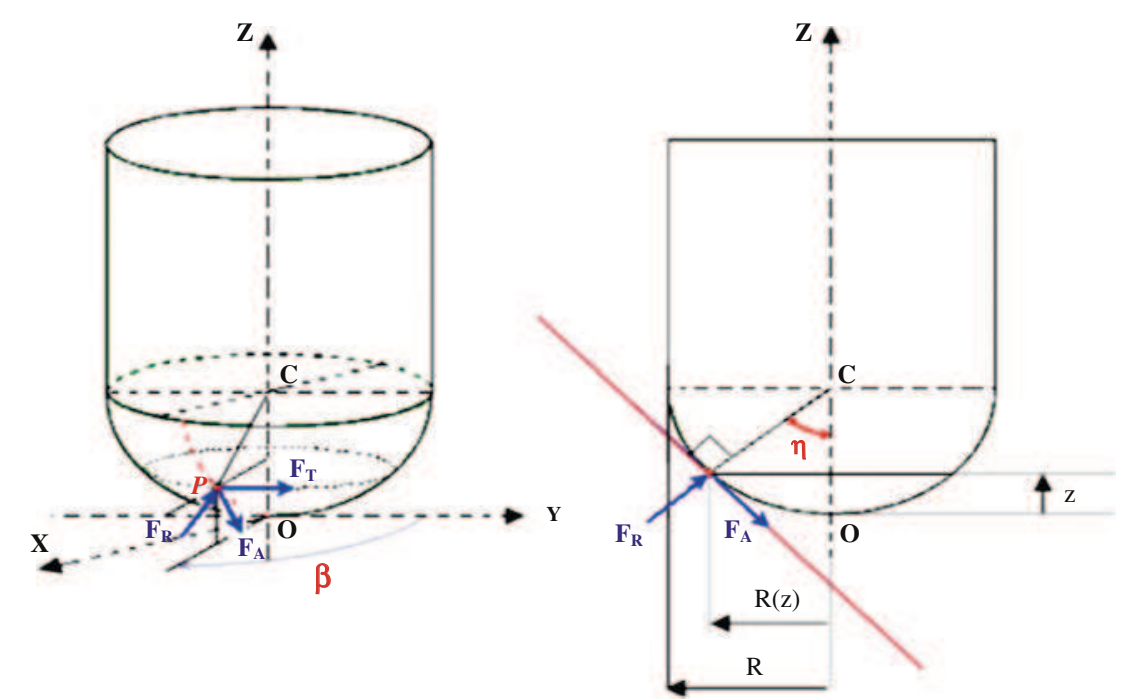
Fig. 3 Couple tool/material used in the experiments
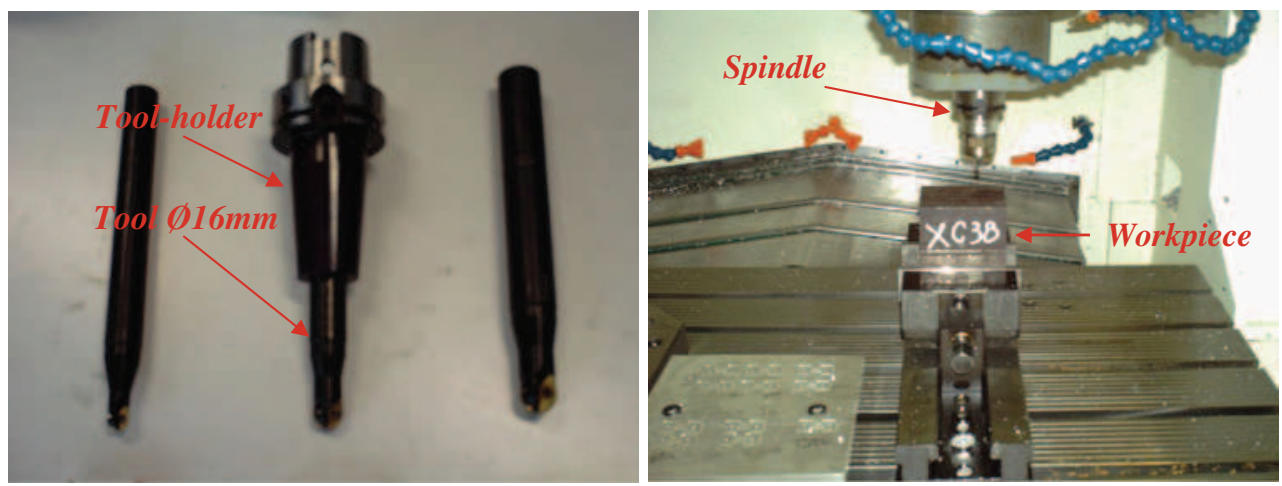

They also allow us to record a difference in amplitude between two consecutive teeth. This gap is due to a problem tool eccentricity according to the spindle axis.

The average of these two different amplitudes will be used for the forces simulation and for the determination of specific coefficients.

The specific coefficients obtained at the time of the test respond to the following values:

$K_{A}=500 N / \mathrm{mm}^{2}$

$K_{T}=3,600 N / \mathrm{mm}^{2}$

$K_{R}=3,400 N / \mathrm{mm}^{2}$

This same mode can be used in the case of an inclined surface of an angle $\alpha$ following the axis $X$, and adopting a change in the coordinate system, dependent on the inclination angle. Afterwards, a generalization is carried out in the case of a circular surface, by using a change of the coordinate system, according to the inclination angle, which varies at each increment, all along the trajectory [7].

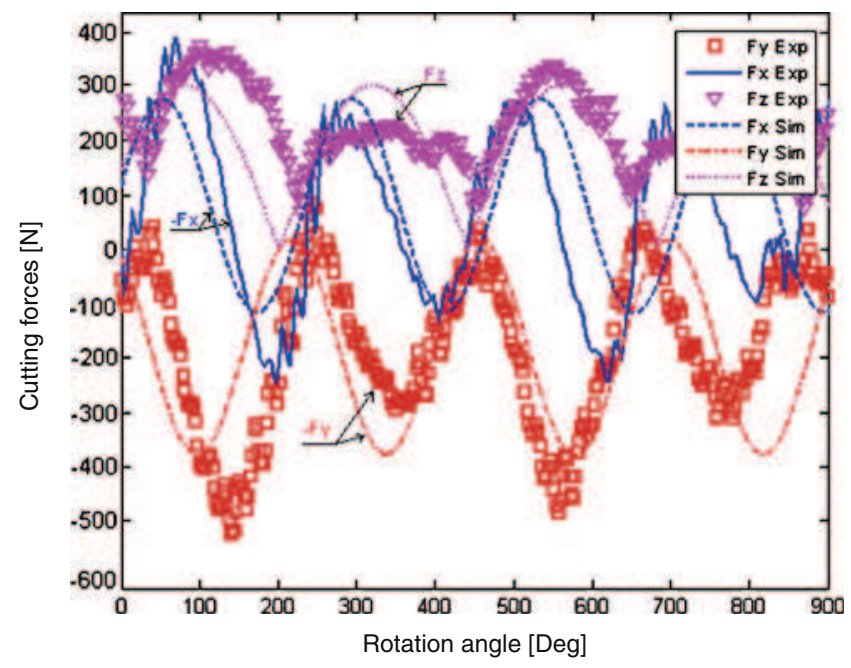

Fig. 4 Simulated and real cutting forces exerted on the dynamometric plate
Figure 5 shows evolution in the cutting forces for different values of $\alpha$ which is the inclination angle according to the horizontal. This angle is valid for the simulation of the cutting forces in the case of the inclined surface milling which is realized by means of a program elaborated on Matlab $\odot$ software.

The tool used here is a ball-end tool of a ray equal to $8 \mathrm{~mm}$, having two teeth $\left(N_{f}=2\right)$ and an angle of helix $i_{0}=9^{\circ}$. This tool fits in the workpiece with a feed of a value $f_{\mathrm{zb}}=0.1 \mathrm{~mm} /$ tooth and an axial depth of cut $A_{d}=$ $1 \mathrm{~mm}$.

Figure 6 shows that the angle of inclination $\alpha$ also exerts an influence on the amplitude of the maximal forces $F_{\mathrm{x}}, F_{\mathrm{y}}$, and $F_{\mathrm{z}}$ in both directions of machining (following $X$, direction 1 ; or $-\mathrm{X}$, direction 2 ).

\section{The modeling of the cutting tool deflection}

There exist two methods for the deflection calculation in literature: the AM and a numerical method of the FEM.

\subsection{Deflection prediction by the AM}

This model supposes that the ball-end cutting tool is a cylindrical beam fixed at one end while the other extremity is ball-shaped.

It is supposed that the tool bears a load F located at a contact point $\mathrm{P}$, as shown in Fig. 7. The tool is composed of two parts: a cylindrical part (AB) of a length $l_{c}=70 \mathrm{~mm}$, of a moment of inertia $I_{c}$, and a second spherical part of a length $l_{s}=10 \mathrm{~mm}$ and of a moment of inertia $I_{s}$.

Knowing the equation of the bending moments $M$ according to $x_{1}$ (position all along the tool; Fig. 7) the slope $d x^{\prime}$ and the deflection $d x$ can be obtained by successive integrations from:

$M=-E \cdot I_{c / s} \cdot d x^{\prime \prime}$

with $M$ the bending moment (equation in $x_{1}$ ), $I_{c / s}$ the moment of inertia of the cylindrical or spherical part and $d x^{\prime \prime}$ the second derivative of the deflection $d x$. 


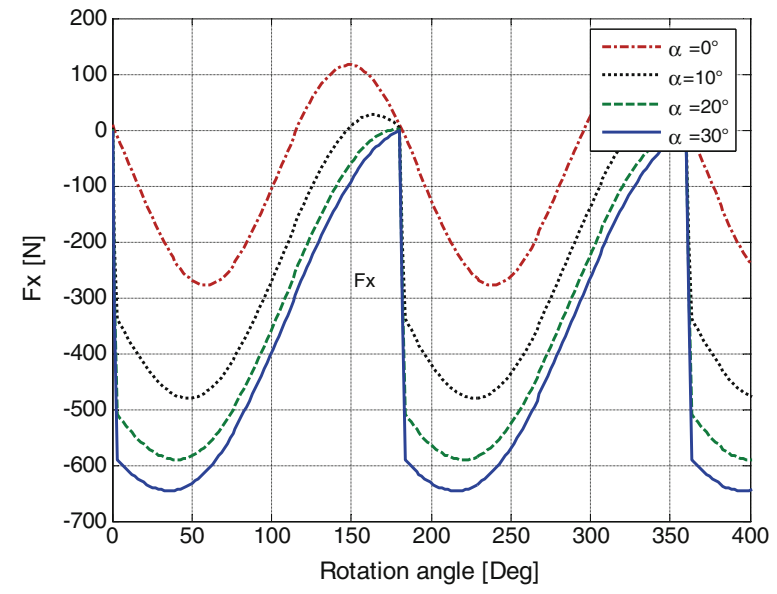

a) The effect of the inclination angle $\alpha$ upon $F_{x}$

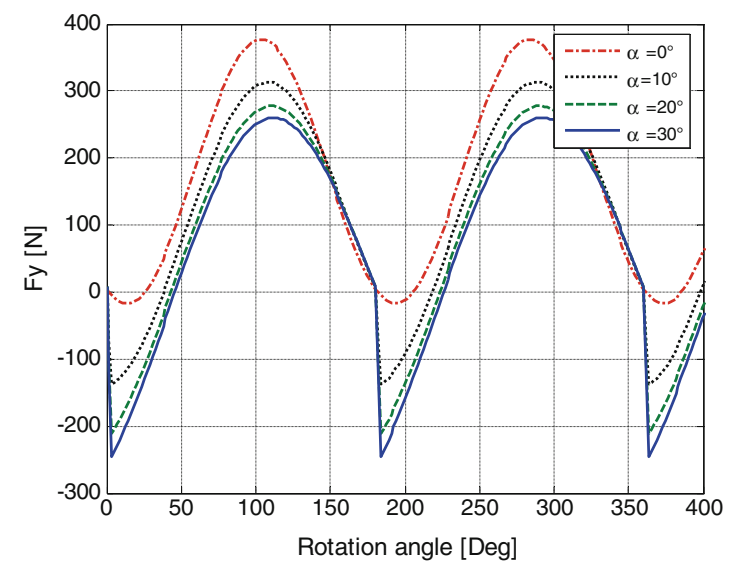

b) The effect of the inclination angle $\alpha$ upon $F_{y}$

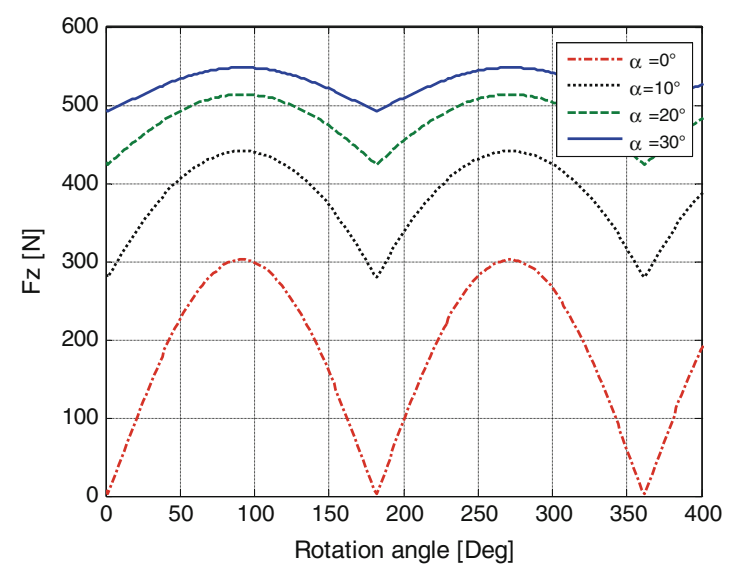

c) The effect of the inclination angle $\alpha$ upon $F_{z}$

Fig. 5 Influence of the inclination angle $\alpha$ on the evolution of the cutting forces

The bending moment is defined according to the position of beam that is:

- Between A and B:

We have : $E \cdot I_{c} \cdot d x^{\prime \prime}=-M=-F \cdot x_{1}+F \cdot l_{F}$

Or $: E \cdot I_{c} \cdot d x^{\prime}=-F \cdot \frac{x_{1}^{2}}{2}-F \cdot x_{1} \cdot l_{F}+C_{1}$

At the point of $A, x_{1}=0, \mathrm{dx}^{\prime}=0 \Rightarrow C_{1}=0$ For a second integration of (9), we obtain:

E.I. $d x=-F \cdot \frac{x_{1}^{3}}{6}+F . l_{F} \cdot \frac{x_{1}^{2}}{2}+C_{2}$

At the point of $\mathrm{A}$, for $x_{1}=0$ we have $d x=0 \Rightarrow C_{2}=0$ The deflection equation following $x_{1}$ belongs to [AB]:

$d x=-\frac{F}{6 \cdot E \cdot I_{c}} \cdot x_{1}^{3}+\frac{F \cdot l_{F}}{2 \cdot E \cdot I_{c}} x_{1}^{2}$

- Between B and C:

we have : $E \cdot I_{s} \cdot d x^{\prime \prime}=-M=F\left(l_{c}-x_{1}\right)+F \cdot l_{s}$ or $d x^{\prime \prime}=\frac{F}{E \cdot I_{s}} \cdot\left(l_{c}-x_{1}\right)+\frac{F}{E \cdot I_{s}} \cdot l_{s}$

A double integration of $d x^{\prime \prime}$ is being used with the conditions of continuity of the beam in B for a length $l_{\mathrm{c}}$. The deflection expression following $x_{1}$ belongs [BC]:

$$
\begin{aligned}
d x= & -\frac{F}{6 \cdot E \cdot I_{s}}\left(x_{1}-l_{c}\right)^{3}+\frac{F \cdot l_{s}}{2 \cdot E \cdot I_{s}}\left(x_{1}-l_{c}\right)^{2}+\frac{F}{E \cdot I_{c}}\left(x_{1}=l_{c}\right) \cdot\left(l_{F} \cdot l_{c}-\frac{l_{c}^{2}}{2}\right) \\
& +\frac{F \cdot l_{c}^{2}}{6 \cdot E \cdot I_{c}}\left(3 \cdot l_{F}-l_{c}\right)+\frac{F}{6 \cdot E \cdot I_{c}} x_{1}^{3}-\frac{F \cdot l_{F}}{2 \cdot E \cdot I_{c}} x_{1}^{2}
\end{aligned}
$$

The total deflection of the tool following the axis $X$, due to the effort $F$, is the sum of the two Eqs. 13 and 16 is given by the following expression:

$$
\begin{aligned}
d x= & -\frac{F}{6 \cdot E \cdot I_{s}}\left(x_{1}-l_{c}\right)^{3}+\frac{F \cdot l_{s}}{2 \cdot E \cdot I_{s}}\left(x_{1}-l_{c}\right)^{2}+\frac{F}{E \cdot I_{c}} \\
& \times\left(x-l_{c}\right)\left(l_{F} \cdot l_{c}-\frac{l_{c}^{2}}{2}\right)+\frac{F \cdot l_{c}^{2}}{6 \cdot E \cdot I_{c}}\left(3 l_{F}-l_{c}\right)
\end{aligned}
$$




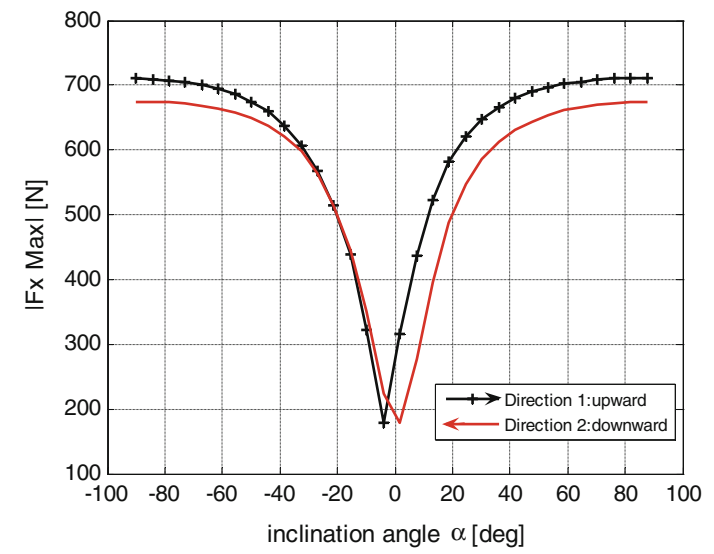

a) The effect of the inclination angle $\alpha$ upon $\left|F_{x \max }\right|$

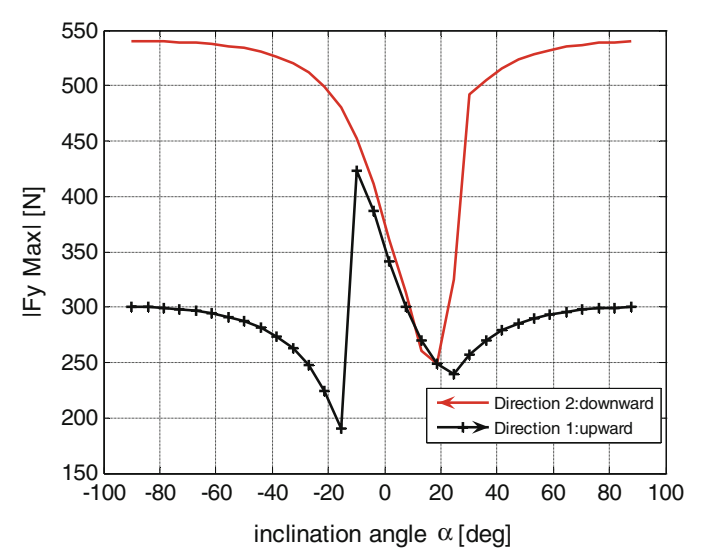

b) The effect of the inclination angle $\alpha$ upon $\left|F_{\text {ymax }}\right|$

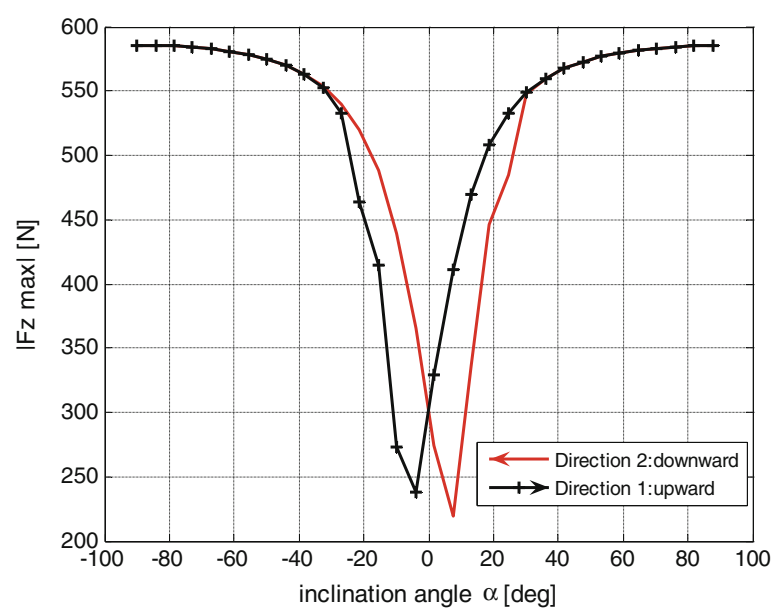

c) The effect of the inclination angle $\alpha$ upon $\left|F_{z \max }\right|$

Fig. 6 The effects of the inclination angle $\alpha$ upon the maximal force amplitude

Figure 8 presents the flexion for a tool of a circular section, of a diameter $d=16 \mathrm{~mm}$, a height $l=80 \mathrm{~mm}$, of Young's modulus $E=207,000 \mathrm{MPa}$ and having a Poisson's ratio $\gamma=0.33$. It is to notice that the deflection increases and it is proportional to the force as well as to the tool length. The declivity of the curve is the inverse of the tool stiffness

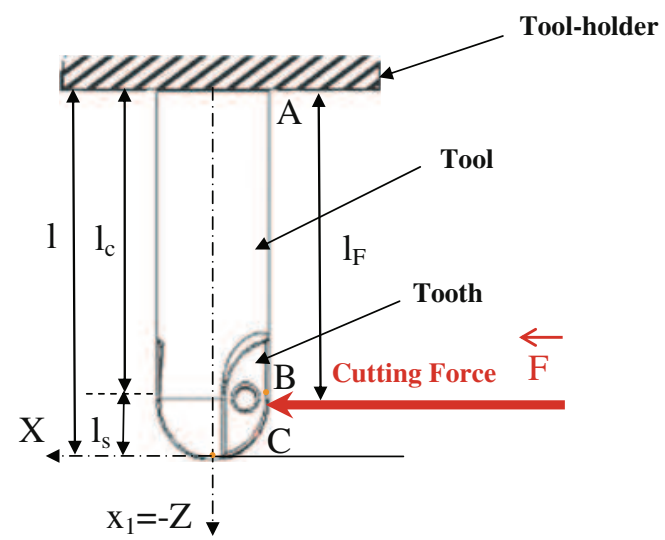

Fig. 7 The loading of the tool which depended from the geometric parameter of the tool and its material. The surface errors would be deduced by the component of deflection $(d x)$.

\subsection{The deflection prediction by the FEM}

The FEM consists in modeling the tool in a first step with the help of CAD system (a ball-end tool of an apparent

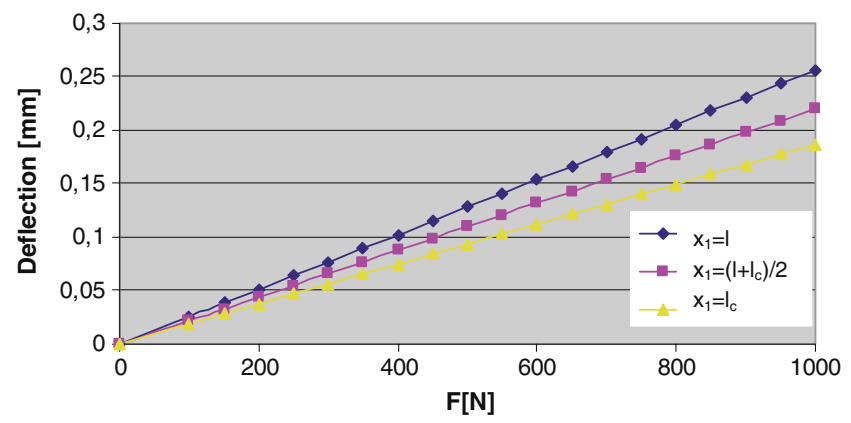

Fig. 8 The evolution of the deflection according to the force $F$ 
$80 \mathrm{~mm}$ length and of a $16 \mathrm{~mm}$ diameter) and also in applying effort to its extremity, to see its elastic behavior. According to the force applied in a given direction, it is a question of deducing the tool tridimensional displacement. The tool used is supposed to be elastic, homogenous, isotropic of Young's modulus $\mathrm{E}=207,000 \mathrm{MPa}$ and of a Poisson's ratio $\gamma=0.33$

The tool modeling by the finite elements method with the ABAQUS software takes into account all the tool geometrical parameters.

The mesh chosen for this purpose is of linear tetrahedral elements of type C3D4. The obtained model is composed of 14,681 nodes and 75,584 elements.

The boundaries conditions are specified in such a way that the extremity of the milling cutter is fixed in the spindle.

Figure 9 presents the tool behavior further to the force exerted following the $X$ direction $(F=1,000 \mathrm{~N})$.

Figure 10 presents the tool deflection according to the three directions $X, Y$, and $Z$, for a load varying from 0 to $1,000 \mathrm{~N}$, has exerted following the axis $X$. The values are simulated by the FEM.

Noting that, further to the application of an effort $F_{\mathrm{x}}$, the displacement following the axis $Z$ is almost nil, whereas the displacement following the force axis is the most important and reaches its maximum value at the extremity of the tool with a value equal to $0.2664 \mathrm{~mm}$ for a force $F_{\mathrm{x}}=1,000 \mathrm{~N}$ (Fig. 9). This deflection increases perceptibly simultaneously with the force of the theoretical study.

The tool deflection due to the force $F_{\mathrm{x}}$ equals:

$\left\{\begin{array}{c}d x_{F x}=a_{1} \cdot F_{x} \text { with } \mathrm{a}_{1}=2,66410^{-4} \\ d y_{F x}=b_{1} \cdot F_{y} \text { with } \mathrm{b}_{1}=-3,0310^{-6} \\ d z_{F x}=c_{1} \cdot F_{z} \text { with } \mathrm{c}_{1}=4,00210^{-5}\end{array}\right.$

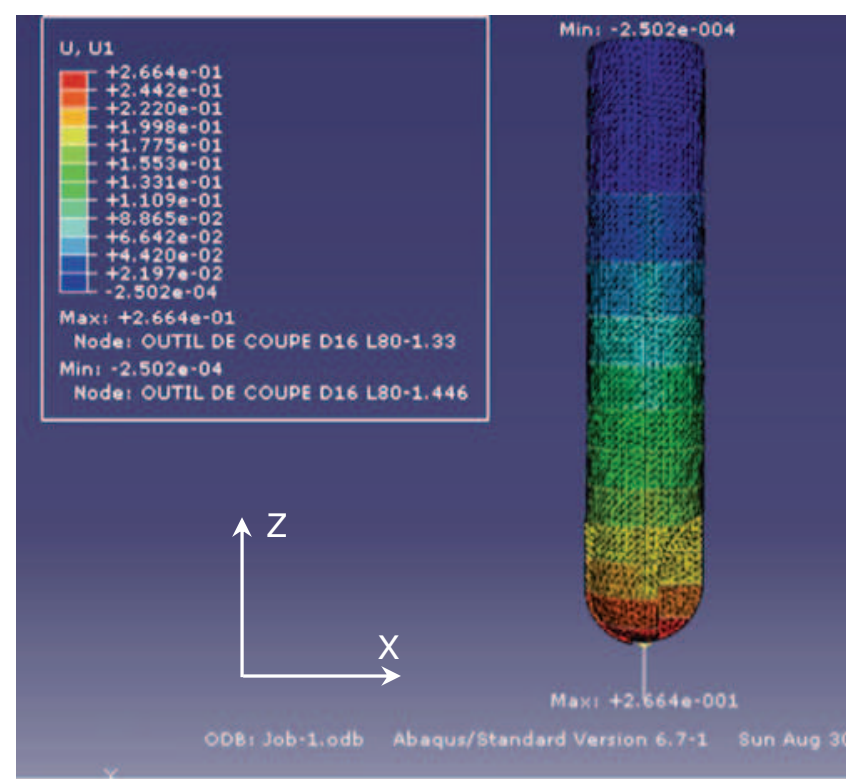

Fig. 9 Deflection $\left(d x_{F x}\right)$ following the axis $X$ for $F=1,000 \mathrm{~N}$

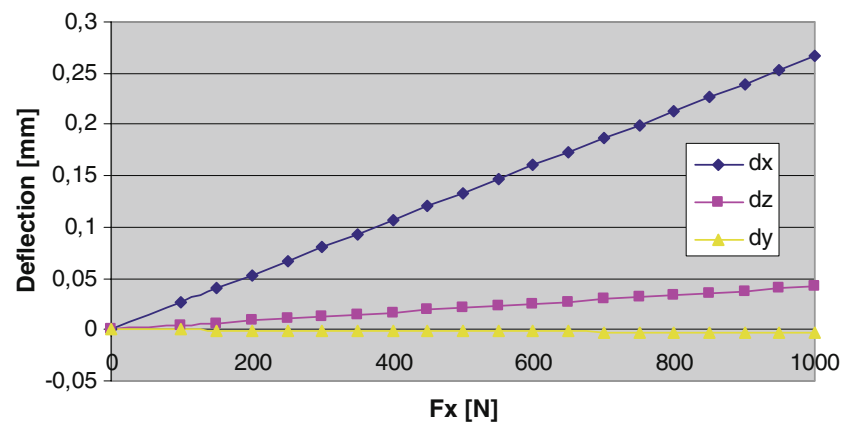

Fig. 10 The tool deformation evolution according to the effort exerted

Similar results are obtained when the force is applied following the axis $\mathrm{Y}$. The tool deflection due to the force $\mathrm{F}_{\mathrm{y}}$ equals:

$\left\{\begin{array}{c}d x_{F y}=a_{2} \cdot F_{x} \text { with } \mathrm{a}_{2}=2,9810^{-6} \\ d y_{F y}=b_{2} \cdot F_{y} \text { with } \mathrm{b}_{2}=2,6410^{-4} \\ d z_{F y}=c_{2} \cdot F_{z} \text { with } \mathrm{c}_{2}=3,79410^{-5}\end{array}\right.$

In order to study and analyze the tool behavior due to the force $F_{\mathrm{z}}$, a load will be applied following the $Z$ axis.

The tool deflection due to the force $F_{\mathrm{z}}$ :

$$
\left\{\begin{array}{l}
d x_{F z}=a_{3} \cdot F_{x} \text { avec } \mathrm{a}_{3}=-2,949 \cdot 10^{-7} \\
d y_{F z}=b_{3} \cdot F_{y} \text { avec } \mathrm{b}_{3}=-2,595 \cdot 10^{-7} \\
d z_{F z}=c_{3} \cdot F_{z} \text { avec } \mathrm{c}_{3}=7,793 \cdot 10^{-6} .
\end{array}\right.
$$

The cutting tool deflection will be more important when the apparent length of the tool increases and its diameter diminishes.

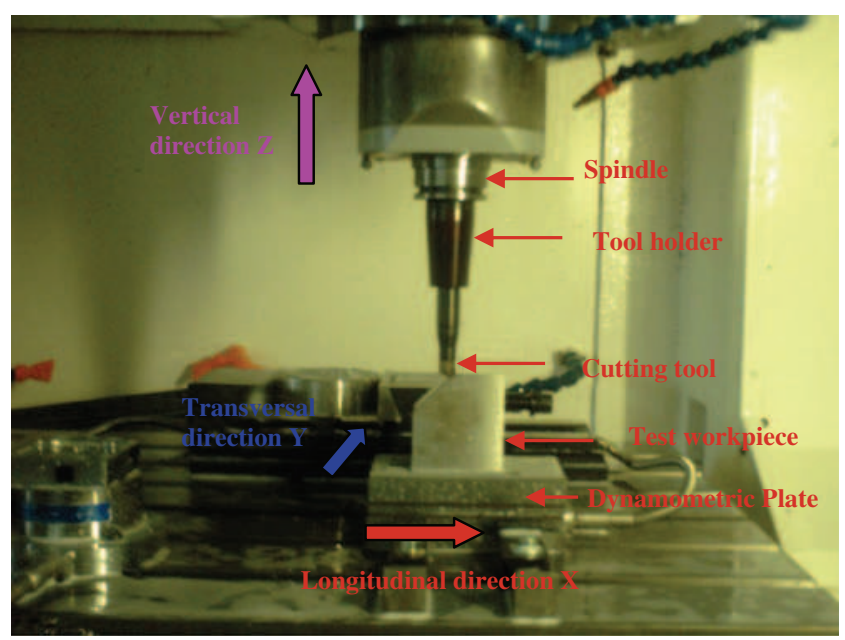

Fig. 11 Tool deflection measuring method on tool machine 
Fig. 12 Cutting forces for an imposed deflection

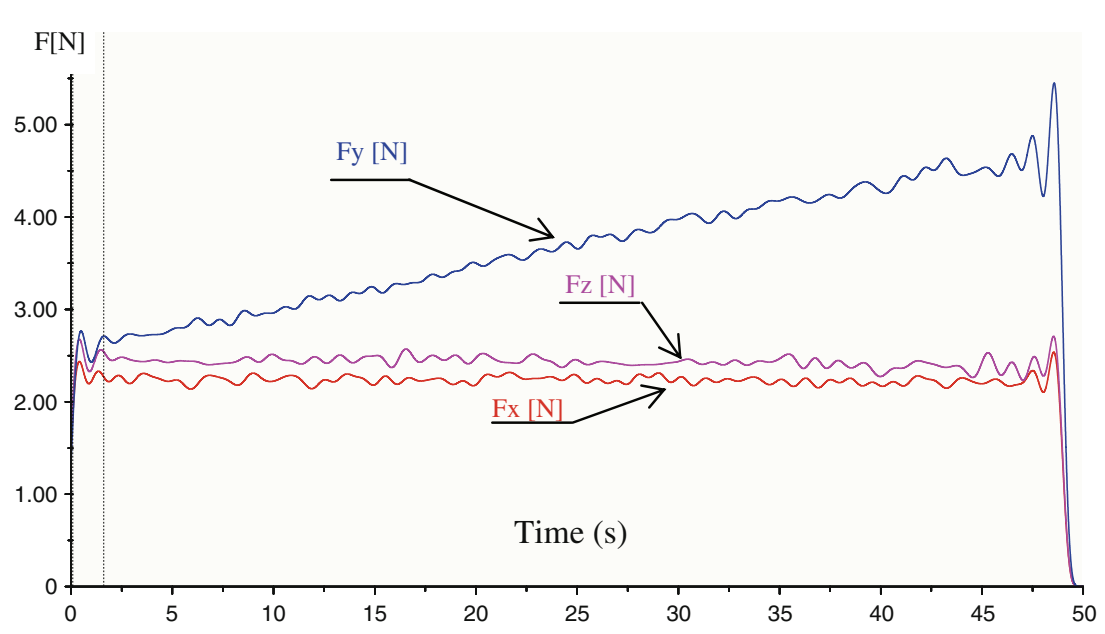

\subsection{Measurement of the cutting force deflection}

In order to measure the tool deflection and experimentally compare it to the results obtained by the two methods: the analytical model and FEM, a milling machine has been used. It is equipped with a cutting forces measure bed, and a simple workpiece which is slightly drilled to prevent the tool from sliding. This practical method consists in causing the tool to be tangent at its extremity to the workpiece while at rest, the machine being out of work (Fig. 11). Afterwards, the transversal bed of a known increment is going to be displaced of $0.001 \mathrm{~mm}$ to measure the value of the force $F_{\mathrm{y}}$. It is not recommended to reach a high value of the deflection, because then, there is a risk of causing the breaking of the machine spindle.

According to the tool displacement, the cutting forces measuring in its extremity, with the help of the dynamometric plate, is represented in Fig. 12:

The tool deflection equation has a linear behavior and equal coefficient of 0.3436 for an intensity of $1,000 \mathrm{~N}$.

3.4 Comparison of the three methods: the AM, FEM, and experimental

Once the deflection has been determined by the three methods, namely the analytical model, the FEM method, and the experimental method, the comparison of these three processes is proving necessary. For this purpose, two curves according to the force which represent the obtained deflection are drawn (Fig. 13).

The values obtained with the finite elements method are directly compared to the results obtained with the analytical model. So the main error in percentage is equals to $4 \%$, this uncrucial difference is justified by the fact that in the case of FEM, the deflection is more important since we consider the spherical part of the tool with its two hollow ventricles, it is then less dense because it contains less matter. Whereas in the AM case, this spherical ball is treated in its totality as a whole.

Noting that the curve given by the experimental method is located in a further position than the two other curves obtained by the two other methods.

These two methods register a relative error of $22 \%$ even though they seem to be very much similar.

This gap can be explained by the fact that the experimental method takes into account a visible deflection, not only of the tool, but also of the whole tool holder/tool structure deviated according to the spindle.

\subsection{Choice between the three proposed methods}

According to the standards, the result of the experimental method is certainly the nearest ones. They are more precise than those provided by the two other methods. However, the FEM is chosen in order to calculate the tool deflection because it is more practical and complies with any tool length and any material.

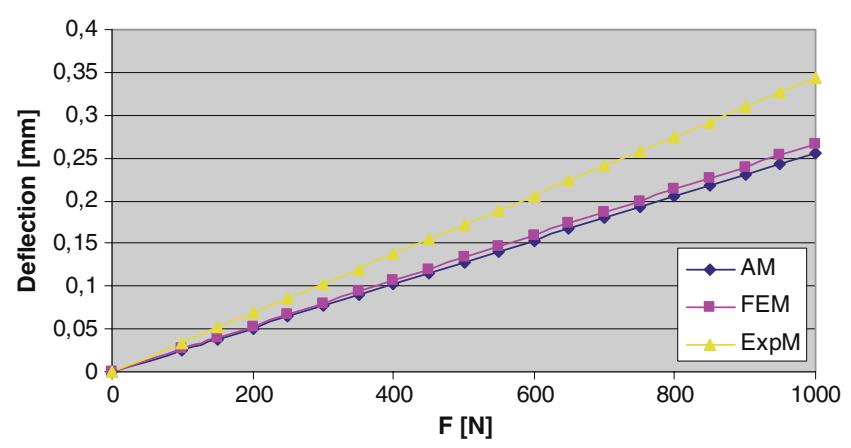

Fig. 13 The deflection evolution, according to the load of the tool, recorded with the three methods: the AM, FEM, and Exp 
Fig. 14 The tool deflection in the directions $X, Y$, and $Z$

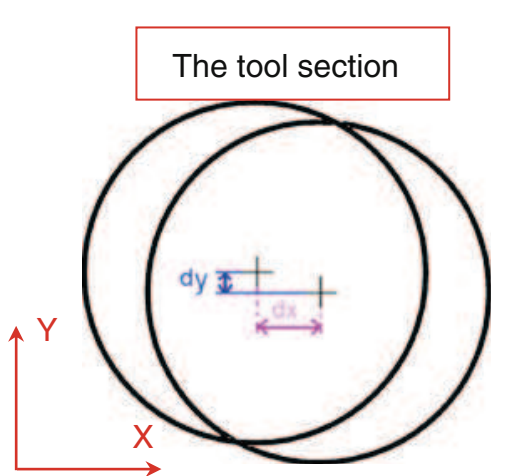

a) The tool deflection in the XY plane.

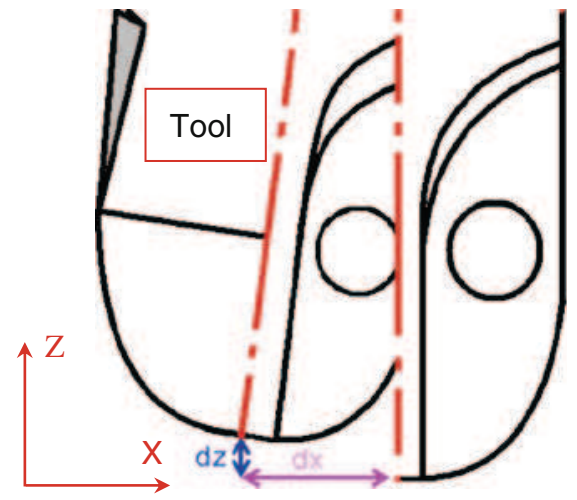

b) The tool deflection in the XZ plane.
The analytical model seems to be acceptable and also practical from diverse points of view. However, it remains a handicap since it does not take into consideration the tool deflection, following the axis $Z$, when this deflection proves to be quite important because the force in this direction is not negligible at all.

For the following step of this work, it is to note that the next adopted method is the FEM since it reveals more accuracy. Besides, it takes into account all the details of the tool complex shape. Moreover, this method allows to measure the deflection following the three axes $X, Y$, and $Z$.
3.6 The tool deflection model

Once the cutting forces are determined, all along the tool trajectory, our choice is oriented towards the finite elements method in order to determine the tool deflection.

These deflections $d x, d y$, and $d z$ are defined in the three directions according to the forces $F_{\mathrm{x}}, F_{\mathrm{y}}$, and $F_{\mathrm{z}}$ as shown in Fig. 14.

From the three Eqs. 18, 19, and 20, it is possible to determine the total deflection which is the sum of the flexions due to the forces $F_{\mathrm{x}}, F_{\mathrm{y}}$, and $F_{\mathrm{z}}$ following the axis $X, Y$, and $Z$ :

$\left\{\begin{array}{c}d x=d x_{F x}+d x_{F y}+d x_{F z}=2,66410^{-4} \cdot F_{x}+2,9810^{-6} \cdot F_{y}-2,949 \cdot 10^{-7} \cdot F_{z} \\ d y=d y_{F x}+d y_{F y}+d y_{F z}=-3,0310^{-6} \cdot F_{x}+2,6410^{-4} \cdot F_{y}-2,595 \cdot 10^{-7} \cdot F_{z} \\ d z=d z_{F x}+d z_{F y}+d z_{F z}=4,00210^{-5} \cdot F_{x}+3,79410^{-5} \cdot F_{y}+7,793 \cdot 10^{-6} \cdot F_{z}\end{array}\right.$

\section{Application}

We want to carry out the milling of a complex workpiece having six surface shapes: plane, inclined upward, concave circular, convex circular, inclined downward and plane, with a length $L=220 \mathrm{~mm}$ and a width $l=78 \mathrm{~mm}$, as indicated in Fig. 15.

The tool used here is the same as the one used in the case of a flat surface milling and in the same cutting conditions.
The cutting forces are calculated according to the nature of the trajectory part (flat, inclined...) and following the machining direction (following $X$ or $-X$ ).

Figure 16 shows the cutting forces evolution, following the tool-end trajectory. This trajectory is obtained from the coordinates of the points transferred from the software "MasterCam". It is of a zig-zag type since the tool carries out several go-and-backs, following $X$ and $-X$, which respectively correspond to an upward cut and a downward

Fig. 15 Workpiece to be machined in $3 \mathrm{D}$
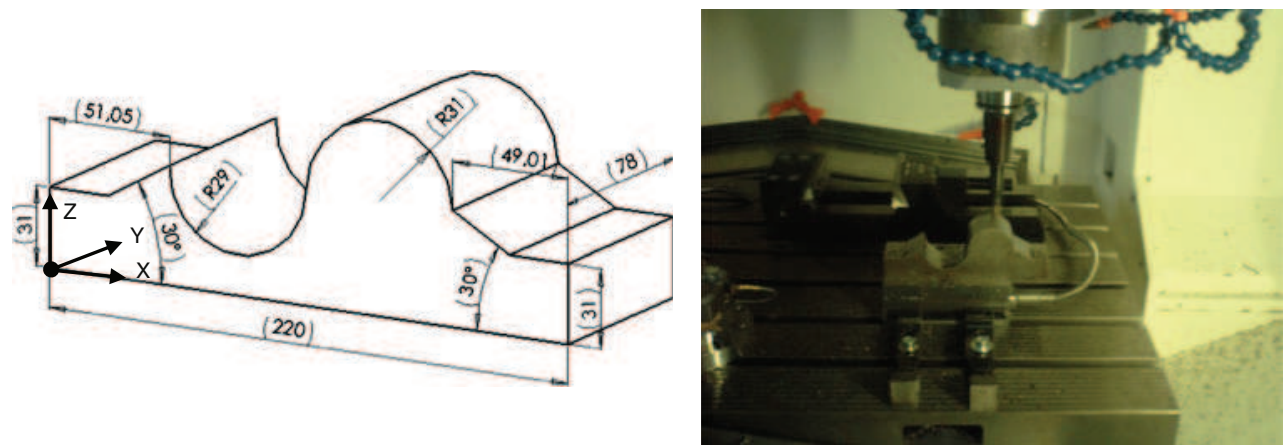
Fig. 16 Cutting forces simulation in longitudinal milling

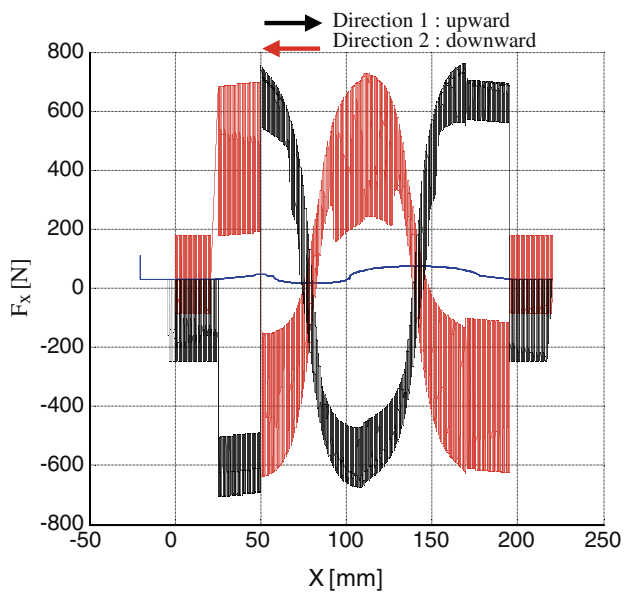

a) $F_{x}$

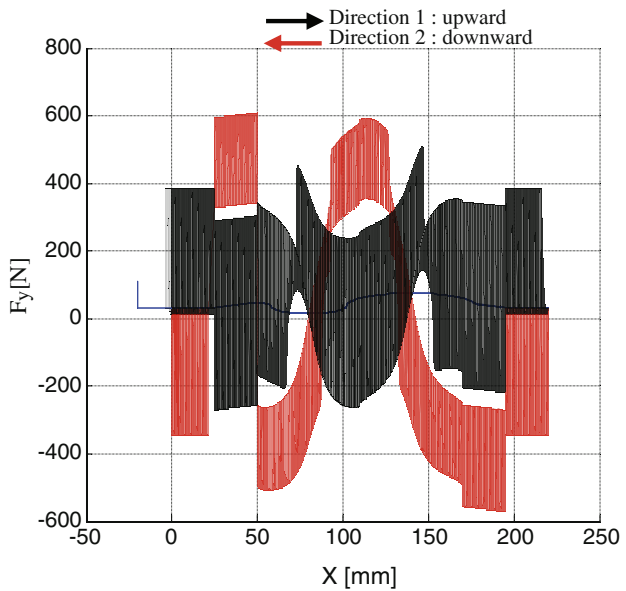

b) $F_{y}$

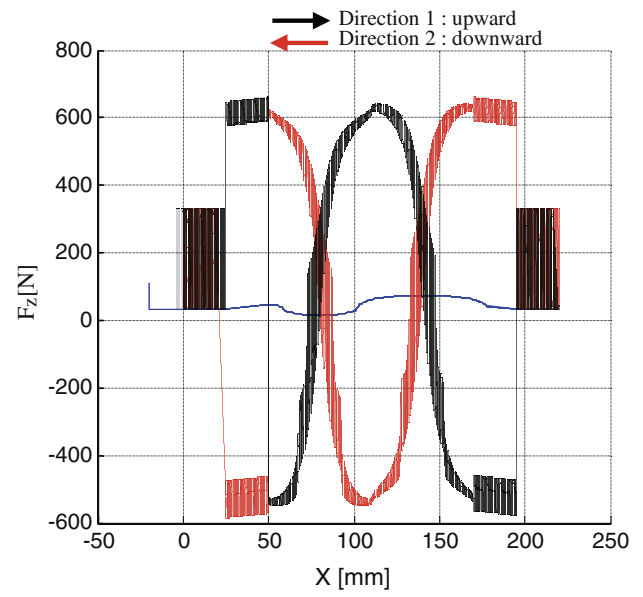

c) $F_{z}$

cut. The cutting forces are drawn in black for the $X$ machining, and in red for the $-X$ machining.

The obtained trajectory, in Fig. 16, is the desired path, seeing that it does not take into account the tool deflection. In fact, further to the cutting forces applied onto the tool, the latter undergoes a deflection in the three directions. The CAM trajectory deviates from its direction of a value $d x, d y$, and $d z$, respectively, to the directions $X, Y$, and $Z$ (Fig. 17). The adopted trajectory is the reflection of the initial trajectory CAM onto the deflected trajectory, delimited by a tolerance interval and chosen all around each of the points forming the CAM vector (Fig. 18).

In reality, if all the points used at the time of the simulation with Matlab are considered, the curve takes a
Fig. 17 Aspect of the two trajectories CAM and deflected
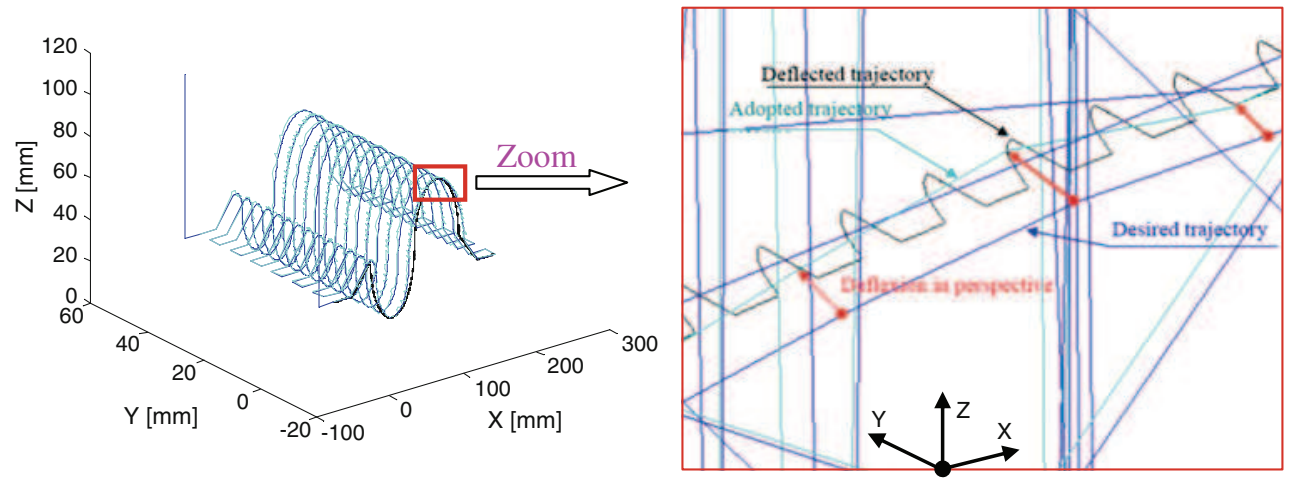


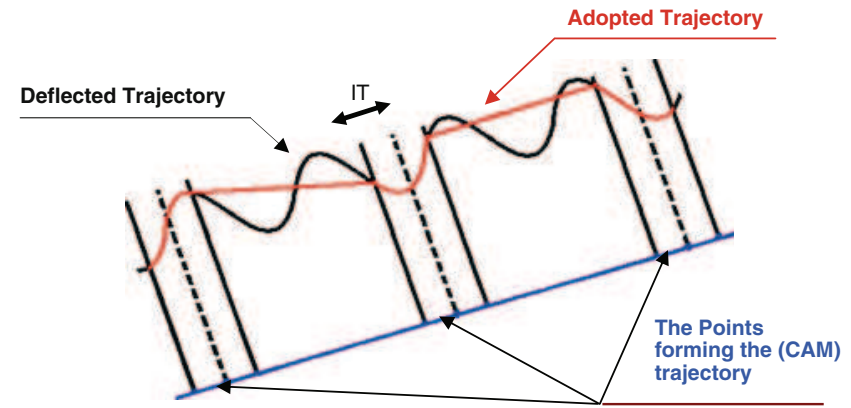

Fig. 18 A part of the adopted trajectory

new precise aspect (deflected trajectory). This precision requires a considerable number of points. This provides a better precision in spite of the slowness of the execution.

Figure 19 represents the aspects of the tool trajectory (CAM and adopted) in the plan $X Z$ for the two machining directions $(X$ and $-X)$.

In order to better clarify the aspect of the different trajectories, and to show their tridimensional aspects, in Fig. 20 the different trajectories are represented in the same machining zone, framed in Fig. 19 at the plan XY.

The coordinates of the nodes forming the deflected (adopted) trajectory are gathered in a vector. It is on this trajectory that the correction of the tridimensional trajectory is going to be executed with the mirror method. This leads to find the compensated trajectory which is going to be sent towards the machine (Fig. 21), by means of a numerical control file generated by the CAM software MasterCam $\mathrm{O}$.

\section{Conclusion}

This paper aimed at proposing a method to simulate the cutting tool deflection trajectory due to the forces applied

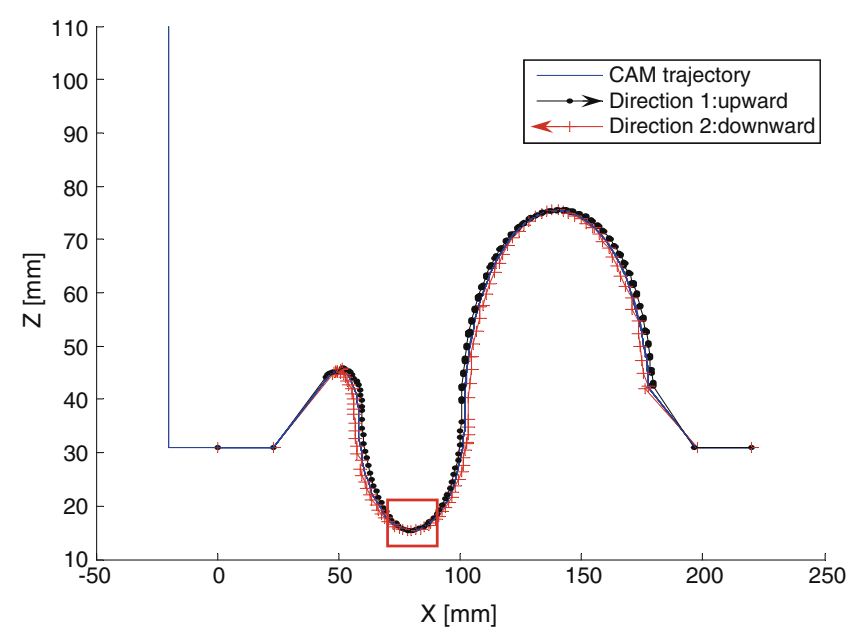

Fig. 19 The tool deflected trajectory in both machining directions in the plan $X Z$

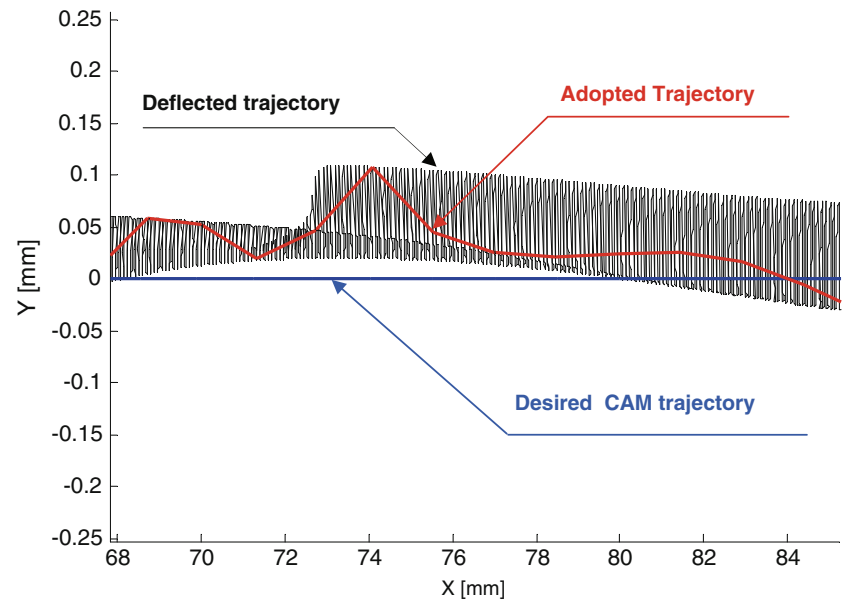

Fig. 20 The desired, deflected and adopted trajectories in the plan $X Y$

on the tool machining. In order to achieve this task, it is necessary to present the calculation process of the cutting forces. The latter are calculated following a discretization of the tool spherical part into a series of disks. The elementary cutting tools are determined. A sum of these forces has allowed to calculate the total cutting force.

Afterwards, three methods aiming at determining the cutting tool deflection have been proposed namely the analytical model, the FEM, and the experimental method (Exp). An error of $4 \%$ between FEM and the AM can be explained by the fact that the FEM takes into consideration the tool exact geometry. Likewise, a gap of $22 \%$ between the Exp and the FEM can be justified by the fact that the experimental method takes into account a visible deflection, not only of the tool, but also of the whole tool holder/tool structure, deviated according to the spindle. The deflection value obtained by the FEM can be closer to the reality (Exp) if we modelize the tool altogether with its tool holder.

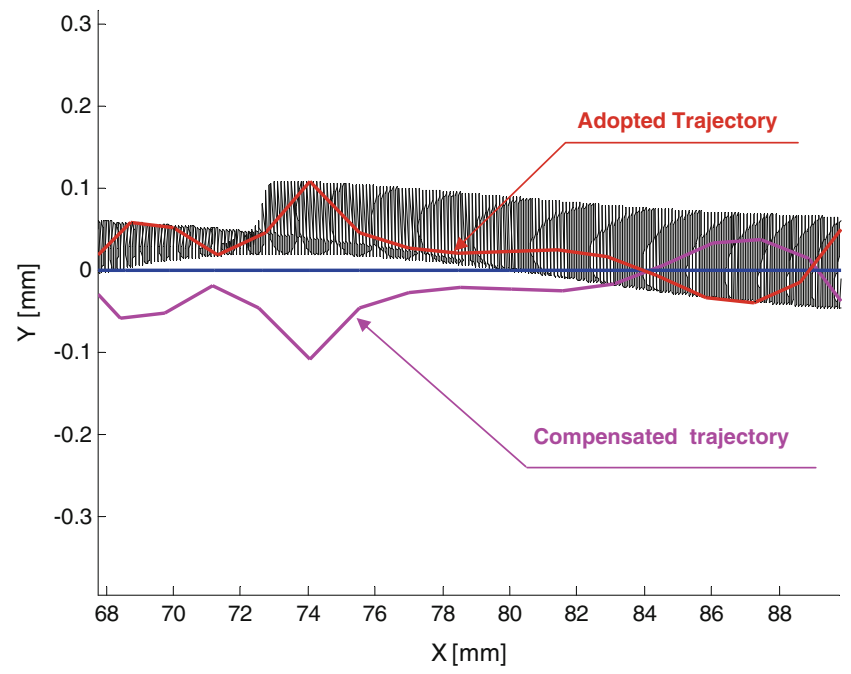

Fig. 21 The tool trajectory compensated 
Our choice has been fixed on the finite elements method. It is believed to be less risky and more practical since it takes into account any geometry of a cutting tool.

The three-dimensional deflections of the tool in the three directions $d x, d y$, and $d z$ are measured by means of the FEM. These deflections are determined according to the cutting forces $F_{\mathrm{x}}, F_{\mathrm{y}}$, and $F_{\mathrm{z}}$. The CAM trajectory is replaced by a series of points, a number of which are taken from the deflected trajectory. These points are gathered in a vector and delimited by a tolerance interval, chosen all around each of the points, forming the CAM trajectory. This vector constitutes the cutting tool-deflected trajectory.

Following this simulation, we are considering to carry on our research and envisage a method of compensation which tends to correct the errors resulting from this deflection.

\section{References}

1. Budak E, Altintas Y (1994) Peripheral milling conditions for improved dimensional accuracy. Int J Mach Tools Manuf 34:907918

2. Law KMY, Geddam A (2001) Prediction of contour accuracy in the end milling of pockets. Journal of Material Processing Techniques 113:399-405

3. Dépince P, Hascoët JY (2006) Active integration of tool deflection effects in end milling. Part 2. Compensation of tool deflection. Int J Mach Tools Manuf 46:945-956
4. Kang MC, Kim KK, Lee DW, Kim JS, Kim NK (2001) Characterization of inclined planes according to the variations of cutting direction in high speed ball-end milling. Int J Adv Manuf Technol 17:323-329

5. Lechniak Z, Werner A, Skalski K, Kedzior K (1998) Methodology of off-line software compensation for errors in the machining process on the CNC machine tool. J Mater Process Technol 76:42-48

6. Lim EM, Menq CH, Yen DW (1997) Integrated planning for precision machining of complex surfaces-III: compensation of dimensional errors. Int J Mach Tools Manuf 37:1313-1326

7. Smaoui M, Bouaziz Z, Zghal A (2008) Simulation of cutting forces for complex surfaces in ball-end milling. Int J Simul Model 7:57-108

8. Suh SH, Cho JH, Hascoet JY (1996) Incorporation of tool deflection in tool path computation: simulation and analysis. $\mathrm{J}$ Manuf Syst 15:190-199

9. Cho MW, Kim GH, Seo TI, Hong YC, Cheng HH (2006) Integrated machining error compensation method using OMM data and modified PNN algorithm. Int $\mathrm{J}$ Mach Tools Manuf 46:1417-1427

10. Cho MW, Seo TI, Kwon HD (2003) Integrated error compensation method using OMM system for profile milling operation. J Mater Process Technol 136:88-99

11. Seo TI (1998) Integration of tool deflection during the generation of tool path, $\mathrm{PhD}$ thesis. Université de Nantes-Ecole Centrale de Nantes, French

12. Kim GM, Kim BH, Chu CN (2003) Estimation of cutter deflection and form error in ball-end milling processes. Int $\mathrm{J}$ Mach Tools Manuf 43:917-924

13. Salgado MA, Lopez de Lacalle LN, Lamikiz A, Munoa J, Sanchez JA (2005) Evaluation of the stiffness chain on the deflection of end-mills under cutting forces. Int J Mach Tools Manuf 45:727739

14. Milfelner M, Cus F (2003) Simulation of cutting forces in ball-end milling. Robot Comput-Integr Manuf 19:99-106 